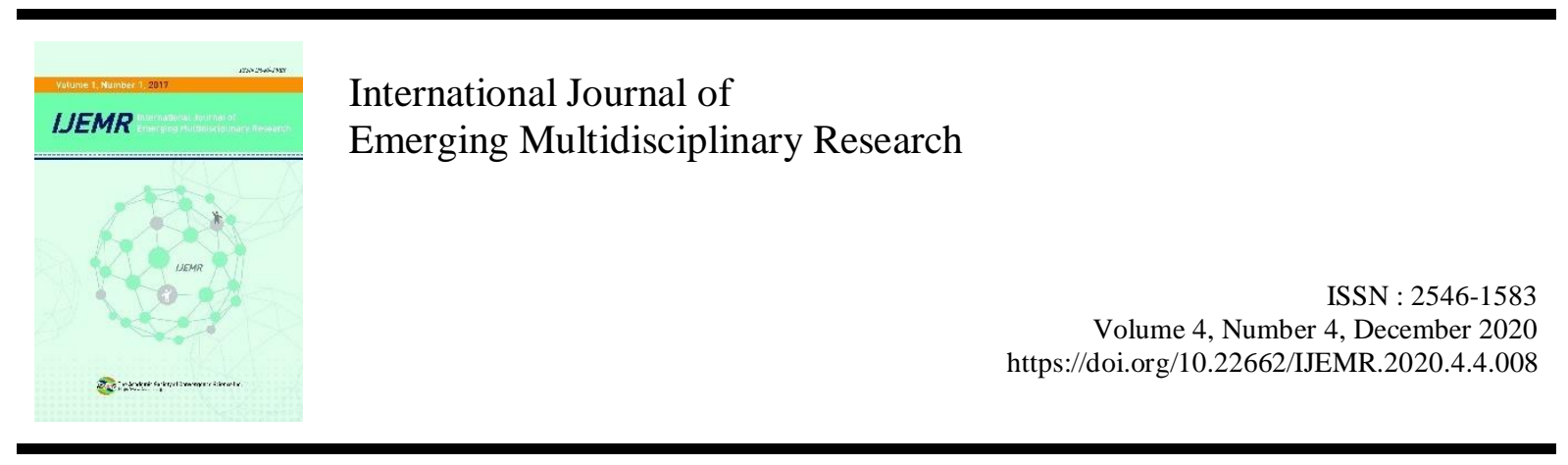

\title{
A Review of Information Seeking Behavior
}

\author{
Hong Jin ${ }^{1}$, Deliang Zhu' ${ }^{2}$ \\ ${ }^{1,2}$ School of Business, Jiangxi Normal University, China
}

\begin{abstract}
Background/Objectives: This article sorts out the literatures of traditional information seeking behavior and social information seeking and looks ahead the research direction of information seeking behavior. Methods/Statistical analysis: This study is a study conducted based on previous studies. That is, it is a review paper. Findings: Based on the results obtained from previous studies, it came to the conclusion that more studies on information seeking behavior are needed. Improvements/Applications: The influence of cognitive factors on social information seeking is rare, and the social information seeking model requires a study that fully considers the effects of cognitive factors.
\end{abstract}

\section{Keyword}

Information seeking behavior, Social information seeking, Information seeking model

\section{INTRODUCTION}

From the beginning to the end of the information seeking, scholars have put forward some information seeking model and done lots of empirical study on the factors of information seeking behavior such as cognitive factor, task factor and so on. These findings are important for people's understanding of information seeking behavior and the improvement of information search systems.

With the advent of Internet era, the original information seeking model - "man-machine" interaction pattern is becoming more and more common, but a new information seeking pattern "social information seeking" is also spring up. There is no doubt that these social systems have a significant impact on the user's information seeking behavior. Social information seeking is a kind of "man-man" interactive information seeking pattern, absolutely, it is bound to inherit and develop the original "manmachine" interaction seeking theory.

On the hand, this review learns and sorts out the traditional information search behavior literature and social information search literature, on the other hand, this review looks ahead the research hotspots.

After of all, this paper puts forward some relevant insights and research direction, hoping to provide some reference and guidance for the further study of information seeking behavior.

\section{Corresponding author : Hong Jin}

342944219@qq.com

- Manuscript received October 1, 2020.

- Revised October 24, 2020 ; Accepted November 8, 2020.

- Date of publication December 31, 2020.

(C) The Academic Society of Convergence Science Inc.

2546-1583 @ 2017 IJEMR. Personal use is permitted, but republication/redistribution requires IJEMR permission. 


\section{INFORMATION SEEKING BEHAVIOR}

\section{A. Definition of information seeking behavior}

The concept of information seeking was proposed firstly by Stigler in his famous journal entitled "Information Economics" published in the journal Political Economy.

He argues that the economic entity have to seek for information in order to make the optimal decision. British intelligence scientist Wilson is an famous scholar in this field of information seeking behavior, he argues that information seeking behavior is the purposive seeking for information as a consequence of a need to satisfy some goal. In the course of seeking, the individual may interact with manual information systems (such as a newspaper or a library), or with computer-based systems [1].

But Marchionini argues that information seeking behavior is the process that people engage in order to change the knowledge state [2].

In the study of information seeking behavior, systemoriented information search and user-oriented information seeking are often mixed. Wilson's embedded model reveals the relationship between information seeking behavior and information search behavior.

Information searching behavior is a subject of information seeking behavior, its purpose is to explore the way people find and obtain different information resources, focusing on information users how to use information systems to obtain information [3].

\section{B. Definition of information seeking behavior}

The construction of the information seeking model is the focus of scholars' research, and scholars often express the process of information seeking by a model.

Dervin ( 1972 ) proposed the sense-making theory. In this theory, the information seeking process is divided into "specific context - cognitive differences information use" three stages, she believes that the searchers encounter problems, information needs, in order to solve the problem, searchers will establish a "bridge" to fill the ditch, this process called "sense making" [4].

Ellis ( 1989 ) sum up the most important six features of information seeking behavior: Staring, Chaining, Browsing, Differentiating, Observation, Extraction. Different individuals have common feature, the information retrieval system should be improved based on the searcher's features[5].

Kuhlthau (1991) proposed a six-stage model based on user perspective. The model takes the whole process of information seeking into account. The process of information seeking is divided into six stages: Initiation, Selection, Exploration, Formulation, Collection, Presentation, integrating the emotional, thinking and tasks and other cognitive factors into the various stages[6].

Wilson(1996) proposed the most classic model of information seeking behavior, the model involves the entire cycle of information search process from a macro perspective. The information seeking behavior was viewed as part of the entire information communication process[3].

Savolainen (2013) proposed a cognitive model based on network competence, which takes the network capacity, self-efficacy, outcome expectations, emotion, and experience into account. This model pays attention to the relation between self-efficiency and network capacities [7].

The advantage of social cognitive model is that it takes the influence of network technology network capability into account, which has been neglected by predecessors.

\section{SOCIAL INFORMATION SEEKING}

\section{A. Definition of social information seeking}

Social information seeking is different from the traditional information seeking behavior. It is a "manman" interactive social information seeking pattern.

We need to recognize the information seeking behavior in the new environment. Evans argues that any information seeking containing social interaction can be viewed as social information seeking, and the purpose of social interaction and collaboration is to promote information seeking and sense making[8].

Croft argues that social information seeking refers to the information seeking containing social interaction[9]. Chi's definition of social information seeking is more extensive, any information seeking using the social resources can be viewed as social information seeking [10].

It is necessary to distinguish social information seeking form collaborative information seeking. Collaborative information seeking emphasizes the cooperation, but social information seeking emphasizes the interaction between man and man, such as information communication or knowledge sharing.

\section{B. Social information seeking model}

Ramirez (2002) proposed the first socialized information seeking model, which incorporated the socialized information seeking strategy, the influencing factors of social information seeking behavior and the search results[11].

Summarized information seeking behavior to the seeking strategy, which was divided to interactive, active, extractive, passive searching . The searcher can simultaneously or sequentially select different search strategies.

Evans and Chi (2010) proposed the canonical social 
model, which divides the socialized information seeking into three phases: before seeking, searching, and after seeking[10]. The information exchange and sharing behavior of the self-motivated searcher and external-motivated searcher in different stages were explored.

The model is better to consider the whole process of information seeking. Results show that the searcher has a strong social tendency, and will take the initiative to share information to others to help others search in the information seeking process.

Compared with the traditional "man-machine" interactive information seeking model, "man-man" interactive social information seeking model can be better to describe the process of social information seeking.

The existing research on the social information seeking model is still less, which didn't take the impact of cognitive factors into account, it is necessary to be further study.

\section{CONCLUSION}

With the advent of the Internet era, we are getting drowned in the Internet information. It is critical for anyone to seek for the necessary information quickly and effectively. As one of the important behavior of people living and working, information seeking behavior need to be studied further on the basis of the existing researches.

Firstly, the scholars need study the cognitive factors of information seeking behavior comprehensively. There are few studies on the integration of each cognitive factor, so it is necessary to do the comprehensive research into the influence of each cognitive factor in the information seeking behavior.

Secondly, the dynamic process of information seeking behavior need to be studied further. In order to complete a task and conduct information seeking behavior, people will continue to seek in the process of information seeking.

The information need and emotional state will change, but the existing research generally only considers the static influence rather than dynamic research. Last but not least, the influencing factors of traditional information seeking pattern need to be tested on social information seeking.

Social information seeking is a new seeking pattern. Account for the search environment underwent great changes, so the original theories remains to be reexamined.

Especially the cognitive factors, the impact of existing cognitive factors on social information seeking is rare, the social information seeking model does not fully consider the impact of cognitive factors, so we need to explore further on social information seeking.

\section{REFERENCES}

[1] Wilson, T. D. (2000). Human information behavior. Informing science, 3(2), 49-56.

[2] Marchionini, G. (1997). Information seeking in electronic environments (No. 9). Cambridge university press.

[3] Wilson, T. D. (1999). Models in information behaviour research. Journal of documentation, 55(3), 249-270.

[4] Dervin, B. (1983, January). An overview of sensemaking research: concepts, methods and results to date. INTERNATIONAL COMMUNICATIONS ASSOCIATION ANNUAL MEETING.

[5] Ellis, D. (1989). A behavioural approach to information retrieval system design. Journal of documentation.

[6] Kuhlthau, C. C. (1991). Inside the search process: Information seeking from the user's perspective. Journal of the American society for information science, 42(5), 361-371.

[7] Savolainen, R. (2015). Approaching the affective factors of information seeking: The viewpoint of the Information search process model.

[8] Evans, B. M., \& Chi, E. H. (2010). An elaborated model of social search. Information Processing \& Management, 46(6), 656-678.

[9] Croft, W. B., Metzler, D., \& Strohman, T. (2010). Search engines: Information retrieval in practice (Vol. 520, pp. 131-141). Reading: Addison-Wesley.

[10] Chi, E. H. (2009). Information seeking can be social. Computer, 42(3), 42-46.

[11] Ramirez Jr, A., Walther, J. B., Burgoon, J. K., \& Sunnafrank, M. (2002). Information-seeking strategies, uncertainty, and computer-mediated communication: Toward a conceptual model. Human communication research, 28(2), 213-228. 